\title{
Final analysis of colorectal cancer patients treated with irinotecan and 5-fluorouracil plus folinic acid neoadjuvant chemotherapy for
} unresectable liver metastases

\author{
C Barone*,', G Nuzzo², A Cassano', M Basso', G Schinzari', F Giuliante ${ }^{2}$, E D’Argento', N Trigila', A Astone' \\ and C Pozzo'
}

'Unit of Medical Oncology, Department of Internal Medicine, Catholic University of Sacred Heart, Rome, Italy; ${ }^{2}$ Unit of Hepatobiliary Surgery, Department of General Surgery, Catholic University of Sacred Heart, Rome, Italy

\begin{abstract}
We have previously reported that neoadjuvant therapy with modified FOLFIRI enabled nearly a third of patients with metastatic colorectal cancer (mCRC) to undergo surgical resection of liver metastases. Here, we present data from the long-term follow-up of these patients. Forty patients received modified FOLFIRI: irinotecan $180 \mathrm{mg} \mathrm{m}^{-2}$, day I; folinic acid, $200 \mathrm{mg} \mathrm{m}^{-2}$; and 5-fluorouracil: as a $400 \mathrm{mg} \mathrm{m}^{-2}$ bolus, days I and 2, and a 48-h continuous infusion $1200 \mathrm{mg} \mathrm{m}^{-2}$, from day I. Treatment was repeated every 2 weeks, with response assessed every six cycles. Resected patients received six further cycles of chemotherapy postoperatively. Nineteen (47.5\%) of 40 patients achieved an objective response; 13 (33\%) underwent resection. After a median follow-up of 56 months, median survival for all patients was 31.5 months: for non-resected patients, median survival was 24 months and was not reached for resected patients. Median time to progression was 14.3 and 5.2 months for all and non-resected patients, respectively. Median disease-free (DF) survival in resected patients was 52.5 months. At 2 years, all patients were alive (8 DF), and at last follow-up, eight were alive (6 DF). Surgical resection of liver metastases after neoadjuvant treatment with modified FOLFIRI in CRC patients achieved favourable survival times.
\end{abstract}

British Journal of Cancer (2007) 97, 1035 - 1039. doi:I0.1038/sj.bjc.6603988 www.bjcancer.com

Published online 25 September 2007

(c) 2007 Cancer Research UK

Keywords: colorectal cancer; irinotecan; FOLFIRI; liver metastases; neoadjuvant

Worldwide, colorectal cancer (CRC) is the fourth most common malignancy in men and the third most common in women. In 2002, the disease accounted for more than one million new cancer cases and caused 528978 deaths (Parkin et al, 2005). Approximately $25 \%$ of CRC patients present with metastatic disease, with the liver being the most common site of metastasis. Over time, $40-50 \%$ of newly diagnosed CRC patients will develop metastatic disease (Saltz et al, 2000). The 5-year survival rate for patients with metastatic CRC (mCRC) is 5-30\% (Van Cutsem et al, 2005).

Patients who are able to undergo resection of isolated liver metastases have the chance of cure or improved survival. If cases are carefully selected for surgery, the 5-year survival rate may be as high as $60 \%$ (Fernandez et al, 2004; Pawlik et al, 2005). However, only $10-20 \%$ of patients with $\mathrm{mCRC}$ are suitable for liver resection at presentation (Adam, 2003). Over the last 10 years, the introduction of two new active cytotoxic chemotherapy drugs and several targeted biological agents has improved the outlook for

*Correspondence: Dr C Barone, Unit of Medical Oncology, Catholic University of Sacred Heart, Largo Francesco Vito, I, Rome 00 I 68, Italy; E-mail: carlobarone@rm.unicatt.it

Received 16 May 2007; revised 27 July 2007; accepted 14 August 2007; published online 25 September 2007 patients with mCRC. Median survival times in excess of 20 months can now be expected with the first- and second-line use of irinotecan and/or oxaliplatin in combination with 5-fluorouracil (5-FU)/folinic acid (FA). This compares favourably with the 12-14 months previously achieved with 5-FU/FA alone (Douillard et al, 2000; Thirion et al, 2004).

These more active chemotherapy regimens are also associated with higher response rates of 39-62\% (Bismuth et al, 1996; Douillard et al, 2000; Saltz et al, 2000; Tournigand et al, 2004; Alberts et al, 2005; Kohne et al, 2005). In addition, as many as $68 \%$ of responding patients with initially unresectable liver disease have been reported to be subsequently eligible for secondary resection of their metastases (Alberts et al, 2005). Indeed, the importance of maximising response rates in this setting was highlighted by the retrospective analysis of Folprecht et al (2005), which demonstrated a strong correlation between response and resection rates, especially in selected patients with no disease outside the liver.

The present study previously reported that $32.7 \%$ of patients with CRC were able to undergo potentially curative surgical resection of initially unresectable liver metastases following neoadjuvant chemotherapy with an irinotecan/5-FU/FA combination (modified FOLFIRI) (Pozzo et al, 2004). This paper reports on the long-term follow-up of these patients, providing data on overall survival, disease-free (DF) survival and time to progression (TTP). 


\section{MATERIALS AND METHODS}

\section{Patients}

Patients aged 18-75 years with unresectable colorectal liver metastases were eligible for entry into the study. Other eligibility criteria were no evidence of extrahepatic disease or involvement of more than $70 \%$ of the liver; Eastern Cooperative Oncology Group (ECOG) performance status of 2 or less; no previous chemotherapy for advanced disease; any adjuvant chemotherapy completed at least 6 months prior to study entry; no history of other malignancies; adequate bone marrow (WBC $>3 \times 10^{9} 1^{-1}$, platelets $>100 \times 10^{9} \mathrm{l}^{-1}$, haemoglobin $>10 \mathrm{~g} \mathrm{dl}^{-1}$ ), liver (total bilirubin $<2 \mathrm{mg} \mathrm{dl}^{-1}$, aspartate aminotransferase or alanine aminotransferase $<3 \times$ upper limit of normal) and renal function (blood urea nitrogen $\leqslant 30 \mathrm{mg} \mathrm{dl}^{-1}$, creatinine clearance $>60 \mathrm{ml} \mathrm{min}^{-1}$, serum creatinine $\leqslant 1.5 \mathrm{mg} \mathrm{dl}^{-1}$ ); and a life expectancy of more than 3 months. Written informed consent was provided by all patients.

\section{Chemotherapy}

Modified FOLFIRI was administered every 2 weeks and consisted of the following: irinotecan $180 \mathrm{mg} \mathrm{m}^{-2}$ given i.v. on day $1 ; 5-\mathrm{FU}$ $1200 \mathrm{mg} \mathrm{m}^{-2}$ continuous i.v. infusion over $48 \mathrm{~h}$ from day 1 ; FA $200 \mathrm{mg} \mathrm{m}^{-2}$ i.v. on days 1 and 2 and 5-FU $400 \mathrm{mg} \mathrm{m}^{-2}$ i.v. bolus on days 1 and 2 . Response was assessed every 12 weeks (six cycles). In cases of neutropaenia $\left(\leqslant 1.5 \times 10^{9} \mathrm{l}^{-1}\right)$, thrombocytopaenia $\left(\leqslant 100 \times 10^{9} 1^{-1}\right)$ or significant non-haematologic toxicity, treatment was delayed for 1 week. In the event of grade $3 / 4$ neutropaenia or diarrhoea, the doses of irinotecan and 5-FU were reduced by $25 \%$. The dose of 5-FU only was similarly reduced in the event of grade 3/4 stomatitis. Treatment was interrupted for grade 4 haematologic toxicity or grade 4 gastrointestinal toxicity (lasting $>1$ week after a previous dose reduction or a delay in dose administration of $>2$ weeks).

Chemotherapy was continued until an objective response was achieved (indicating suitability for surgery), or until disease progression or unacceptable toxicity. Those patients who underwent resection of their liver metastases received six further cycles of the same chemotherapy regimen postoperatively. Patients with progressive disease were treated at the discretion of the investigator.

\section{Assessments}

Initial unresectability of liver metastases was assessed as described previously, using the criteria set out by the institution at which the study was carried out (Pozzo et al, 2004).

\section{RESULTS}

\section{Patients}

Forty patients were enrolled into the study over 2.5 years up to January 2003. The patients' baseline characteristics are outlined in Table 1 . The median age of the patients was 58.7 years (range: $32-$ 75 years) and the majority were male $(60 \%)$. All but one patient had an ECOG performance status of 0 . The majority of patients $(67.5 \%)$ had synchronous metastases, with the remainder being metachronous. At study entry, 21 patients $(52.5 \%)$ had less than three metastases and $11(27.5 \%)$ had more than six. Twelve $(30 \%)$ patients had at least one lesion $\geqslant 5 \mathrm{~cm}$ in diameter and seven $(17.5 \%)$ patients had metastases that were unfavourably located in the hilum.

Of those patients with liver metastases that were considered to be unresectable, $35 \%$ had large numbers of metastases, $25 \%$ had large metastases, 5\% had inadequate liver reserve and $35 \%$ had surgically inaccessible metastases (Table 1).
Table I Baseline characteristics of patients

\begin{tabular}{ll}
\hline Characteristic & $\mathbf{n}=\mathbf{4 0}$ patients \\
\hline Gender (\%) & 60 \\
Male & 40 \\
Female & $58.7(32-75)$ \\
Median age, years (range) & \\
ECOG performance status (\%) & 97.5 \\
0 & 2.5 \\
I-2 & \\
Metastases (\%) & 67.5 \\
Synchronous & 32.5 \\
Metachronous & \\
Number of metastases (\%) & 52.5 \\
$<3$ & 20 \\
$3-6$ & 27.5 \\
$>6$ & \\
Largest metastasis (\%) & 30 \\
$\geqslant 5$ cm diameter & 70 \\
$<5$ cm diameter & \\
Site of metastasis (\%) & 17.5 \\
Hilum & 82.5 \\
Other sites & \\
Main cause of unresectability (\%) & 35 \\
Number of metastases & 35 \\
Location of metastases & 25 \\
Size of metastasis & \\
Insufficient liver reserve & \\
\hline & \\
\hline
\end{tabular}

ECOG $=$ Eastern Cooperative Oncology Group.

\section{Response to chemotherapy}

As of December 10 2006, median follow-up was 56 months. All 40 patients had been evaluated for response yielding an objective response rate of $47.5 \%$, including two complete responses. Of the $19(47.5 \%)$ patients who experienced an overall response, 16 were considered to be eligible for surgery (after a median of eight cycles of chemotherapy per patient (range: 6-12)) and 13 underwent resection of their liver metastases. The median overall survival of these patients has not yet been reached. The median survival for all 40 patients was 31.5 months (Figure 1A) and in non-resected patients, 24 months (Table 2). Nine out of 40 patients (22.5\% (95\% CI: $10.5-34.5 \%)$ ) were still alive, including one not resected patient. The median TTP for all patients was 14.3 months (range: $2-49$ ), and in non-resected patients, 5.2 months.

\section{Adverse events}

The treatment was well tolerated and the adverse events that were observed and described previously were those typical of the cytotoxic agents used (Pozzo et al, 2004). There were no delayed onset adverse events. There were no significant differences in the incidence and severity of adverse events experienced by patients during the additional postresection chemotherapy phase compared with those reported for the initial phase of treatment.

\section{Surgery}

Among the 13 patients who underwent surgery, there were $13 \mathrm{R} 0$ liver resections. Most of these patients (10 out of 13) underwent multiple segmental resections. As reported previously, the resection rate following chemotherapy was highest in those patients with large $(>5 \mathrm{~cm})$ metastases (6 out of 10) (Pozzo et al, 2004). 

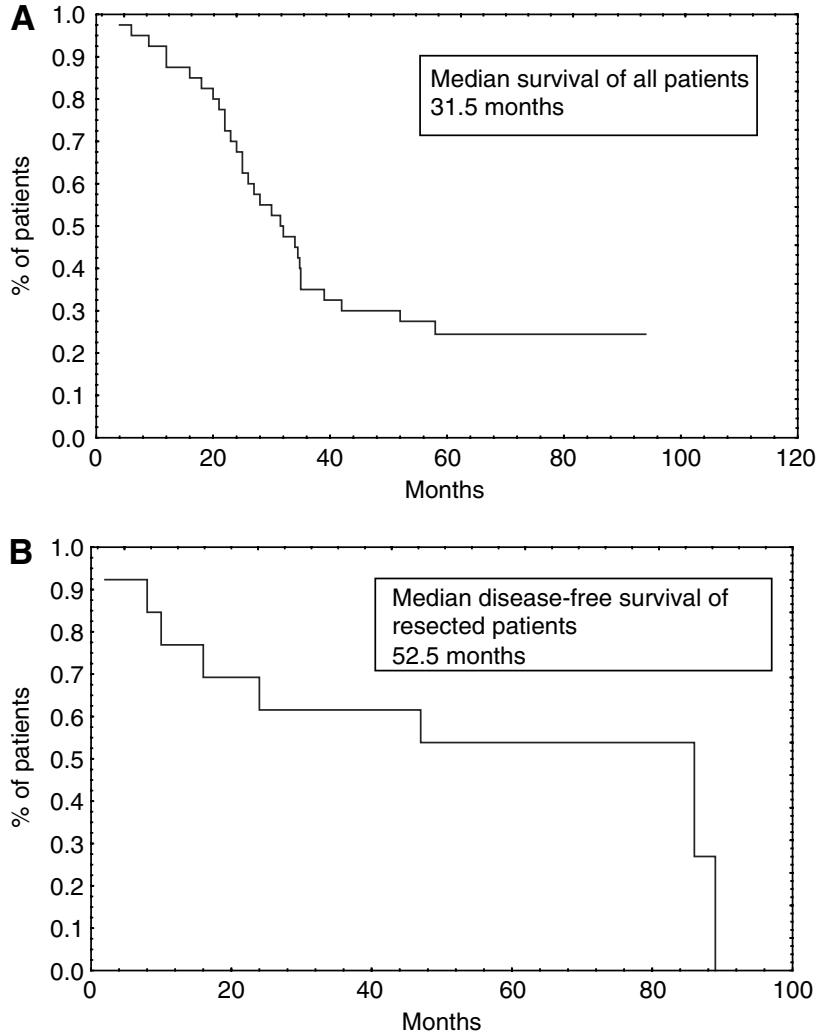

Figure I (A) Median overall survival. (B) Median disease-free survival.

Table 2 Survival and time to progression in resected and non-resected patients

\begin{tabular}{|c|c|c|c|}
\hline & $\begin{array}{l}\text { All patients } \\
n=\mathbf{n 0}\end{array}$ & $\begin{array}{l}\begin{array}{l}\text { Non-resected } \\
\text { patients } n=27\end{array}\end{array}$ & $\begin{array}{c}\text { Resected patients } \\
\qquad n=13\end{array}$ \\
\hline $\begin{array}{l}\text { Median survival, } \\
\text { months (range) }\end{array}$ & $31.5(4-92)$ & 24 & NR \\
\hline $\begin{array}{l}\text { Median TTP, } \\
\text { months (range) }\end{array}$ & | $4.3(2-49)$ & $5.2(2-13)$ & 52.5 \\
\hline $\begin{array}{l}\text { Median DF } \\
\text { survival, months } \\
\text { (range) }\end{array}$ & - & - & $52.5(2-89)$ \\
\hline \multicolumn{4}{|l|}{ Survival (\%) } \\
\hline 6 months & 97.5 & 96.2 & 100 (85\% DF) \\
\hline I-year follow-up & 87.5 & 81.4 & 100 (77\% DF) \\
\hline 2-year follow-up & 63.5 & 55.5 & 100 (62\% DF) \\
\hline \multirow{2}{*}{$\begin{array}{l}\text { Last follow-up } \\
\text { (5 years) }\end{array}$} & 22.5 & 3.7 & 62 (46\% DF) \\
\hline & (95\% Cl: I $0.5,34.5)$ & & $\begin{array}{l}\text { (OS 95\% Cl: } 19.3,72.9) \\
\text { (DF 95\% Cl: } 19.3,72.9)\end{array}$ \\
\hline
\end{tabular}

$\mathrm{Cl}=$ confidence interval; $\mathrm{DF}$, disease-free; $\mathrm{NR}=$ not reached; $\mathrm{OS}=$ overall survival; TTP $=$ time to progression.

Also, there was no postoperative mortality in the 2 months following surgery. One patient experienced anaemia as a consequence of postoperative bleeding (Pozzo et al, 2004).

\section{Disease-free survival}

The median DF survival of the resected patients was 52.5 months (Figure 1B). At the time of reporting, a median of 56 months from resection, $6(46 \%$ (95\% CI: $19.3-72.9 \%))$ of the 13 radically resected patients were still disease free and $8(62 \%)$ of the 13 were still alive (Table 2 ).

\section{DISCUSSION}

After a median follow-up period of nearly 60 months, the median survival for all patients was 31.5 months. This is one of the highest reported median survival times for a prospective study in similar groups of patients treated with standard combinations of cytotoxic agents. Moreover, currently, the median survival time for those patients who underwent secondary resections of their liver metastases has not yet been reached.

It has been recognised for some time that resection of liver metastases offers the best long-term hope for patients with mCRC. Chemotherapy regimens combining 5-FU/FA with irinotecan and/ or oxaliplatin have demonstrated impressive efficacy in the downstaging of liver metastases to permit secondary resection (Van Cutsem et al, 2005) and their role in the neoadjuvant setting is now essentially undisputed. However, as yet, there is no consensus about which neoadjuvant regimen will be the most effective, either in general terms or for particular patients (as defined by disease or genotypic variation). Emerging data suggest that the addition of targeted biological agents to such regimens will further improve efficacy. Indeed, Folprecht et al (2006) reported a median survival time of 33 months, using cetuximab, an EGFRtargeted monoclonal antibody, in combination with irinotecan/5FU/FA. In a randomised phase III trial, cetuximab was shown to increase response rate, progression-free survival and resection rate over FOLFIRI alone in patients with advanced CRC, with the PFS benefit being greatest for those patients with liver-only metastases (Van Cutsem et al, 2007).

One of the factors that have hindered comparisons between studies of neoadjuvant treatment of initially unresectable colorectal liver metastases is that there is no universally accepted definition of unresectability. Patient selection is a crucial factor, both for maximising the benefits achievable from primary resection (Fong et al, 1999) and for enabling the highest resection rates following neoadjuvant therapy (Adam et al, 2004a, b; Folprecht et al, 2005). In their retrospective analysis, Folprecht et al (2005) found that in studies which enrolled patients with metastases confined to the liver, $24-54 \%$ of patients were able to undergo resection of their metastases subsequent to chemotherapy, whereas only $1-26 \%$ of patients in non-selective trials (patients with hepatic or extrahepatic disease) became eligible for secondary surgery. However, this analysis found a strong correlation between the response rate to neoadjuvant therapy and the resection rate in both the selected $(r=0.96, P=0.002)$ and unselected $(r=0.74, P<0.001)$ patients.

Studies of resection following neoadjuvant therapy have also demonstrated long-term benefits. Giacchetti et al (1999) reported that 77 out of 151 (51\%) patients had surgery with curative intent following neoadjuvant treatment with 5-FU/FA/oxaliplatin. Complete resection was achieved in 58 patients. The median survival of the operated patients was 48 months (range: 25-71), and the 5year survival rate was $50 \%$ (range: $38-61$ ). A more recent retrospective analysis by Zaniboni et al (2005) of oxaliplatinbased chemotherapy found an overall response rate of $78.5 \%$ in 105 patients. Ninety-nine patients had liver surgery, with $79 \%$ undergoing radical resection. The median survival time for these patients was 42 months.

In a study using a neoadjuvant combination of 5-FU/FA/ irinotecan/oxaliplatin (FOLFOXIRI) (Masi et al, 2006), there was a response rate of $72 \%$ in unselected patients and a $26 \%$ (19 patients) hepatic resection rate. In five patients, extrahepatic disease was also resected. The median overall survival of surgical patients was 36.8 months, with a 4 -year survival rate of $37 \%$. The 
overall survival of patients who responded to chemotherapy but did not undergo surgery was 22.2 months $(P=0.0114)$. In a randomised phase III trial, FOLFOXIRI improved response rate, progression-free and overall survival compared with FOLFIRI, with secondary R0 resection rates of 15 vs $6 \%$ in non-selected patients and 36 vs $12 \%$ in patients with metastases confined to the liver (Falcone et al, 2007).

A multicentre phase II study investigated the use of irinotecan with 5-FU/FA (FOLFIRI) as neoadjuvant chemotherapy in selected patients with unresectable liver metastases (Ho et al, 2005). The overall response rate was $55 \%$ (22 out of 40 patients: $95 \%$ CI: $39.5-$ $70.4 \%$ ). Median overall survival was 20 months (95\% CI: $17.7-$ 26.6). Four patients underwent resection of metastases and remained alive at a median follow-up time of 33 months.

In the current study, neoadjuvant treatment with FOLFIRI achieved a response rate of $47.5 \%$, with one-third of patients able to undergo secondary resection of liver metastases. Following resection, patients achieved a worthwhile median DF survival of 52.5 months. Median survival (all patients) was 31.5 months after a median follow-up of 56.0 months, and will be higher in radically resected patients, the median survival not yet having been reached. This compares favourably with Ho et al (2005) and other phase II studies in patients with initially unresectable metastases confined to the liver (Folprecht et al, 2005) and confirms the benefit of perioperative chemotherapy demonstrated in the EORTC EPOC trial in patients with resectable liver metastases (Nordlinger et al, 2007). Furthermore, the median overall survival is approaching twice that for unselected, unresected patients reported for combination therapy in the FOCUS (Seymour et al, 2007) and CAIRO trials (Punt et al, 2007).

As the use of neoadjuvant therapy has increased, so has the concern about possible long-term adverse effects of chemotherapy, particularly on the liver, where there is some evidence of vascular changes (Rubbia-Brandt et al, 2004; Adam et al, 2005) and steatohepatitis (Fernandez et al, 2005) following chemotherapy. However, although the vascular changes may increase the risk of intraoperative bleeding, it is not thought that they have any significant clinical impact (Adam et al, 2005).
Also, a retrospective study by Karoui et al (2006) showed that although preoperative chemotherapy was significantly associated with sinusoidal dilatation, atrophy of hepatocytes and/or hepatocytic necrosis (49 vs 25\%, $P=0.005$ ) and increased morbidity, it did not appear to be linked to increased postoperative mortality in those patients who were resected. It is now generally accepted that provided patients are not overtreated with chemotherapy prior to surgery, there is little evidence of increased mortality and morbidity.

Ideally, the overall survival benefit conferred by neoadjuvant treatment needs to be validated in a prospective randomised trial in the palliative setting. Such a trial, in the light of present knowledge, would be ethically unacceptable because it should include a no surgery arm in which patients would not undergo surgery, even if their liver metastases become resectable after chemotherapy. However, prolonged (5 years or more) follow-up of patients, with identification of the particular regimen used to facilitate the resection of liver metastases, may be all that is necessary to fully evaluate the benefits of the different neoadjuvant treatment choices.

What is clear from the results of the current study is that irinotecan combination therapy (FOLFIRI) should be considered for the neoadjuvant treatment of patients with mCRC who have unresectable liver metastases as part of current strategic patient management practices. Future large-scale randomised studies in this setting should therefore include, for comparison, arms that receive irinotecan-based chemotherapy. Additionally, conventional chemotherapy could be combined with one or more molecularly targeted drugs as soon as the data on their role in advanced disease become available (Van Cutsem et al, 2007).

\section{ACKNOWLEDGEMENTS}

No financial support was received for this independent study. However, editorial assistance was provided by Cancer Communications and supported by Pfizer.

\section{REFERENCES}

Adam R (2003) Chemotherapy and surgery: new perspectives on the treatment of unresectable liver metastases. Ann Oncol 14: ii13-ii16

Adam R, Delvart V, Pascal G, Valeanu A, Castaing D, Azoulay D, Giacchetti S, Paule B, Kunstlinger F, Ghemard O, Levi F, Bismuth H (2004a) Rescue surgery for unresectable colorectal liver metastases downstaged by chemotherapy: a model to predict long-term survival. Ann Surg 240: 644-657; discussion 657-658

Adam R, Pascal G, Castaing D, Azoulay D, Delvart V, Paule B, Levi F, Bismuth H (2004b) Tumor progression while on chemotherapy: a contraindication to liver resection for multiple colorectal metastases? Ann Surg 240: 1052-1061; discussion 1061-1064

Adam R, Sebagh M, Plasse M, Karam V, Giacchetti S, Azoulay D, Bouchahda M, Jasmin C, Castaing D, Levi F (2005) Impact of preoperative systemic chemotherapy on liver histology and outcome of hepatic resection for colorectal cancer liver metastases (CRLM). J Clin Oncol 23: $16 \mathrm{~S}$

Alberts SR, Horvath WL, Sternfeld WC, Goldberg RM, Mahoney MR, Dakhil SR, Levitt R, Rowland K, Nair S, Sargent DJ, Donohue JH (2005) Oxaliplatin, fluorouracil, and leucovorin for patients with unresectable liver-only metastases from colorectal cancer: a North Central Cancer Treatment Group phase II study. J Clin Oncol 23: 9243 - 9249

Bismuth H, Adam R, Levi F, Farabos C, Waechter F, Castaing D, Majno P, Engarran L (1996) Resection of nonresectable liver metastases from colorectal cancer after neoadjuvant chemotherapy. Ann Surg 224: 509-520

Douillard JY, Cunningham D, Roth AD, Navarro M, James RD, Karasek P, Jandik P, Iveson T, Carmichael J, Alakl M, Gruia G, Awad L, Rougier P
(2000) Irinotecan combined with fluorouracil compared with fluorouracil alone as first-line treatment for metastatic colorectal cancer: a multicentre randomised trial. Lancet 355: $1041-1047$

Falcone A, Ricci S, Brunetti IM, Pfanner E, Allegrini G, Barbara C, Crino L, Benedetti G (2007) Phase III trial of infusional fluorouracil, leucovorin, oxaliplatin, and irinotecan (FOLFOXIRI) compared with infusional fluorouracil, leucovorin, and irinotecan (FOLFIRI) as first-line treatment for metastatic colorectal cancer: the Gruppo Oncologico Nord Ovest. $J$ Clin Oncol 25: $1670-1676$

Fernandez FG, Drebin JA, Linehan DC, Dehdashti F, Siegel BA, Strasberg SM (2004) Five-year survival after resection of hepatic metastases from colorectal cancer in patients screened by positron emission tomography with F-18 fluorodeoxyglucose (FDG-PET). Ann Surg 240: 438-447; discussion $447-450$

Fernandez FG, Ritter J, Goodwin JW, Linehan DC, Hawkins WG, Strasberg SM (2005) Effect of steatohepatitis associated with irinotecan or oxaliplatin pretreatment on resectability of hepatic colorectal metastases. J Am Coll Surg 200: $845-853$

Folprecht G, Grothey A, Alberts S, Raab HR, Kohne CH (2005) Neoadjuvant treatment of unresectable colorectal liver metastases: correlation between tumour response and resection rates. Ann Oncol 16: 1311-1319

Folprecht G, Lutz MP, Schoffski P, Seufferlein T, Nolting A, Pollert P, Kohne CH (2006) Cetuximab and irinotecan/5-fluorouracil/folinic acid is a safe combination for the first-line treatment of patients with epidermal growth factor receptor expressing metastatic colorectal carcinoma. Ann Oncol 17: $450-456$ 
Fong Y, Fortner J, Sun RL, Brennan MF, Blumgart LH (1999) Clinical score for predicting recurrence after hepatic resection for metastatic colorectal cancer: analysis of 1001 consecutive cases. Ann Surg 230: 309-318

Giacchetti S, Itzhaki M, Gruia G, Adam R, Zidani R, Kunstlinger F, Brienza S, Alafaci E, Bertheault-Cvitkovic F, Jasmin C, Reynes M, Bismuth H, Misset JL, Levi F (1999) Long-term survival of patients with unresectable colorectal cancer liver metastases following infusional chemotherapy with 5-fluorouracil, leucovorin, oxaliplatin and surgery. Ann Oncol 10: $663-669$

Ho WM, Ma B, Mok T, Yeo W, Lai P, Lim R, Koh J, Wong YY, King A, Leow CK, Chan AT (2005) Liver resection after irinotecan, 5-fluorouracil, and folinic acid for patients with unresectable colorectal liver metastases: a multicenter phase II study by the cancer therapeutic research group. Med Oncol 22: $303-312$

Karoui M, Penna C, Amin-Hashem M, Mitry E, Benoist S, Franc B, Rougier P, Nordlinger B (2006) Influence of preoperative chemotherapy on the risk of major hepatectomy for colorectal liver metastases. Ann Surg 243: 1-7

Kohne CH, van Cutsem E, Wils J, Bokemeyer C, El-Serafi M, Lutz MP, Lorenz M, Reichardt P, Ruckle-Lanz H, Frickhofen N, Fuchs R, Mergenthaler HG, Langenbuch T, Vanhoefer U, Rougier P, Voigtmann R, Muller L, Genicot B, Anak O, Nordlinger B (2005) Phase III study of weekly high-dose infusional fluorouracil plus folinic acid with or without irinotecan in patients with metastatic colorectal cancer: European Organisation for Research and Treatment of Cancer Gastrointestinal Group Study 40986. J Clin Oncol 23: 4856-4865

Masi G, Cupini S, Marcucci L, Cerri E, Loupakis F, Allegrini G, Brunetti IM, Pfanner E, Viti M, Goletti O, Filipponi F, Falcone A (2006) Treatment with 5-fluorouracil/folinic acid, oxaliplatin, and irinotecan enables surgical resection of metastases in patients with initially unresectable metastatic colorectal cancer. Ann Surg Oncol 13: 58-65

Nordlinger B, Sorbye H, Collette L, Glimelius B, Poston G, Schlag PM, Rougier P, Bechstein W, Walpole E, Gruenberger T (2007) Final results of the EORTC intergroup randomized phase III study 40983 [EPOC] evaluating the benefit of peri-operative FOLFOX4 chemotherapy for patients with potentially resectable colorectal cancer liver metastases. J Clin Oncol 25: 2S, abstract LBA 5

Parkin DM, Bray F, Ferlay J, Pisani P (2005) Global cancer statistics, 2002. CA Cancer J Clin 55: 74-108

Pawlik TM, Scoggins CR, Zorzi D, Abdalla EK, Andres A, Eng C, Curley SA, Loyer EM, Muratore A, Mentha G, Capussotti L, Vauthey JN (2005) Effect of surgical margin status on survival and site of recurrence after hepatic resection for colorectal metastases. Ann Surg 241: 715-722; discussion $722-724$

Pozzo C, Basso M, Cassano A, Quirino M, Schinzari G, Trigila N, Vellone F, Giuliante F, Nuzzo G, Barone C (2004) Neoadjuvant treatment of unresectable liver disease with irinotecan and 5-fluorouracil plus folinic acid in colorectal cancer patients. Ann Oncol 15: $933-939$

Punt CJ, Koopman M, Douma J, Wals J, Honkoop AH, Erdkamp FL, de Jong RS, Rodenburg CJM, Mol L, Antonini NF (2007) Sequential compared to combination chemotherapy with capecitabine, irinotecan, and oxaliplatin in advanced colorectal cancer (ACC): a Dutch Colorectal Cancer Group (DCCG) phase III study. J Clin Oncol 25: 166S, abstract 4012

Rubbia-Brandt L, Audard V, Sartoretti P, Roth AD, Brezault C, Le Charpentier M, Dousset B, Morel P, Soubrane O, Chaussade S, Mentha G, Terris B (2004) Severe hepatic sinusoidal obstruction associated with oxaliplatin-based chemotherapy in patients with metastatic colorectal cancer. Ann Oncol 15: 460-466

Saltz LB, Cox JV, Blanke C, Rosen LS, Fehrenbacher L, Moore MJ, Maroun JA, Ackland SP, Locker PK, Pirotta N, Elfring GL, Miller LL (2000) Irinotecan plus fluorouracil and leucovorin for metastatic colorectal cancer. Irinotecan Study Group. N Engl J Med 343: 905-914

Seymour MT, Maughan TS, Ledermann JA, Topham C, James R, Gwyther SJ, Smith DB, Shepherd S, Maraveyas A, Ferry DR, Meade AM, Thompson L, Griffiths GO, Parmar MK, Stephens RJ, FOCUS Trial Investigators; National Cancer Research Institute Colorectal Clinical Studies Group (2007) Different strategies of sequential and combination chemotherapy for patients with poor prognosis advanced colorectal cancer (MRC FOCUS): a randomized controlled trial. Lancet 370: $143-152$

Thirion P, Michiels S, Pignon JP, Buyse M, Braud AC, Carlson RW, O'Connell M, Sargent P, Piedbois P (2004) Modulation of fluorouracil by leucovorin in patients with advanced colorectal cancer: an updated metaanalysis. J Clin Oncol 22: $3766-3775$

Tournigand C, Andre T, Achille E, Lledo G, Flesh M, Mery-Mignard D, Quinaux E, Couteau C, Buyse M, Ganem G, Landi B, Colin P, Louvet C, De Gramont A (2004) FOLFIRI followed by FOLFOX6 or the reverse sequence in advanced colorectal cancer: a randomized GERCOR study. J Clin Oncol 22: 229-237

Van Cutsem E, Nowacki M, Lang I, Cascinu S, Shchepotin I, Maurel J, Rougier P, Cunningham D, Nippgen J, Köhne C (2007) Randomized phase III study of irinotecan and 5-FU/FA with or without cetuximab in the first-line treatment of patients with metastatic colorectal cancer (mCRC): The CRYSTAL trial. J Clin Oncol 25: 164S, abstract 4000

Van Cutsem EJ, Oliveira J, Kataja VV (2005) ESMO minimum clinical recommendations for diagnosis, treatment and follow-up of advanced colorectal cancer. Ann Oncol 16(Suppl 1): i18-i19

Zaniboni A, Torri V, Tinazzi A, Codignola C, Faggiuolo R, Sperti E (2005) Neoadjuvant oxaliplatin-based chemotherapy for liver metastases from colorectal cancer. An Italian survey. Tumori 91: 383-387 